DOI: 10.14451/2.159.34

\title{
ПУБЛИЧНО-ПРАВОВОЕ РЕГУЛИРОВАНИЕ ПРЕДПРИНИМАТЕЛЬСКОЙ ДЕЯТЕЛЬНОСТИ И ФОРМИРОВАНИЕ ЦИФРОВЫХ СТАРТАПОВ
}

\author{
(c) 2021 Щукина Татьяна Владимировна \\ доктор юридических наук, доцент, заведующая кафедрой прикладного права \\ РТУ МИРЭА, Россия, Москва \\ (c) 2021 Рассыльников Игорь Александрович \\ кандидат юридических наук, доцент, доцент кафедры прикладного права \\ РТУ МИРЭА, Россия, Москва
}

Предметом настоящей статьи выступает исследование публично-правового регулирования предпринимательской деятельности и цифровых стартапов в Российской Федерации при реализации стратегических задач развития государства. Тема статьи отражает тенденции правовой регламентации цифровых стартапов. Целью настоящей статьи является выявление новых публично-правовых инструментов поддержки малого предпринимательства, прежде всего, цифровых стартапов, технологического предпринимательства по исполнению национальных целей и задач развития Российской Федерации. Кроме того, в статье затронут анализ развития системы публично-правового регулирования предпринимательской деятельности в условиях формирования и развития цифровой экономики в Российской Федерации. Методологию данной работы составили сравнительный, формально-юридический, аналитический методы. Результаты работы - это формулирование роли и содержания новых инструментов правового регулирования различных стартапов в условиях цифровизации и модернизации экономики. Область применения результатов работы включает в себя государственную политику в области стратегического развития и управления.

Ключевые слова: публично-правовое регулирование, стартап, технологическое предпринимательство, цифровая экономика

Экономическая функция государства в обязательном порядке реализуется, в том числе, при помощи государственного регулирования предпринимательской деятельности. В литературе отмечено, «что целью государственного регулирования предпринимательской деятельности является создание определенных условий, обеспечивающих нормальное функционирование экономики в целом, и стабильное участие предпринимателей страны в разделении труда и получение от этого оптимальных выгод. Правительство каждого государства, безусловно, имеет свои собственные цели на каждом конкретном этапе и добивается их решения доступными ему методами и средствами применительно к складывающейся экономической ситуации в своей стране и в мировом хозяйстве. Поэтому цели и задачи государственного регулирования подвержены изменениям, между тем, как механизм регулирования достаточно хорошо отработан, хотя и имеет особенности в каждой отдельно взятой стране» [1]. Реализация экономической функции государства в настоящее время становится солидарной и использует общественные формы, включая объединения предприятий и предпринимателей, а также различные инвестиционные ресурсы.

Развитие инвестиций в Российской Федерации традиционно связывалось с расширением и модернизацией таких отраслей экономической деятельности, как металлургия, добывающая промышленность, электроэнергетика, атомная промышленность. Начиная с 2010-2011 годов, появляются инновационные производства, которые именуют - новыми инновационными стартапами [2]. Впервые стартапы стали создаваться в форме субъектов малого предпринимательства, участвующих в деятельности инновационных территориальных кластеров и технологических платформ [3]. Они поддерживались Фондом содействия развитию малых форм предприятий в научно-технической сфере на основе грантовой программы «Старт». Первоначально стартапы поддерживались и формировались в необходимых для российского государства технологических направлениях развития: информационные технологии, медицина, современные материалы и технологии их созда- 
ния, приборы и аппаратные комплексы, биотехнологии [4].

Данный термин «стартап» прочно вошел в бизнес-лексику и в нормативно-правовое регулирование. Это понятие не облечено в строгое легальное правовое определение. В деловом обороте под «стартапом» обозначается «быстрорастущая компания, которая находится в поиске своей масштабируемой бизнес-модели. Об этом упоминает, в частности, Р.М.Янковский в работе «Закон Стартапа» [5]. В 2020 году в Методических рекомендациях по цифровой трансформации государственных корпораций и компаний с государственным участием, утвержденных Минкомсвязью России 16 января 2020 года, были представлены термины для указанных рекомендаций, среди которых закрепилось правовое определение «Стартап-проект». Под стартап-проектом понимается инновационный комплекс мероприятий, основанный на идее или решении, которые раньше не существовали в компании или не преподносились в таком виде. Подобные стартап-проекты являются элементом цифровой среды.

В обыденном сознании стартапы ассоциируются с субъектами малого и среднего предпринимательства, действующими преимущественно в сфере цифровой экономики. Действительно, цифровые стартапы отвечают критериям малого и среднего предпринимательства, установленным в федеральном законе «О развитии малого и среднего предпринимательства в Российской Федерации» от 24 июля 2007 года. В этих формах стартапы могут рассчитывать на государственную поддержку в традиционных форматах (информационном, имущественном, финансовом). Под цифровыми стартапами понимаются ИТ-стартапы. Они создаются под реализацию направлений по искусственному интеллекту, интернету вещей, блокчейну, новым производственным технологиям и финансируются Фондом «Сколково», Российским фондом развития информационных технологий (РФРИТ), Фондом содействия инновациям. Программа Фонда содействия инновациям (ФСИ) ориентирована на реализацию ИТ-стартапов с грантовой поддержкой от 3 млн. до 24 млн. рублей. Российский фонд развития информационных технологий (РФРИТ) предоставляет гранты до 300 млн. рублей проектам, направленным на разработку программного обеспечения, включая дистанционные сервисы для удаленной работы, платформы для онлайн-образования или здравоохранения [6].В 2020 году на подобные гранты выделено 7,1 млрд. рублей.

В экономическом пространстве стартапы это не только цифровые стартапы, а, как правило, новые малые инновационные / наукоемкие / высокотехнологичные предприятия, образованные на основе использования результатов научных исследований и разработок [7]. Например, в области квантовых коммуникаций [8], генетических технологий, биомедицинские технологии и т.д. Инновационные высокотехнологичные предприятия обретают свой статус, благодаря выпуску инновационной продукции и (или) высокотехнологичной продукции [9]. Инновационная продукция должна отличаться новизной, то есть являться принципиально новой и соответствующей приоритетным направлениям развития науки, технологий и техники в Российской Федерации и (или) перечню критических технологий. Следовательно, с позиций российского законодательства и, по мнению авторов, стартап - это субъект предпринимательской деятельности, функционирующий в традиционных организационно-правовых формах (чаще всего в статусе индивидуального предпринимателя или общества с ограниченной ответственностью) в форме малого и среднего предпринимательства в поддерживаемых государством высокотехнологичных направлениях стратегического развития.

В целях развития стартапов и не только цифровых с 2017 года начинается движение формирования студенческого технологического предпринимательства и создание стартапакселераторов [10] с участием венчурного капитала развития. Вместе с тем, российское законодательство не содержит однозначных понятий цифровой экономики или ИТ-компании, что не всегда способствует пониманию сути и направлений публично-правового регулирования и государственной поддержки в этой сфере. Например, на практике ИТ-компаниями именуют организации или ИП, которые занимаются разработкой, продажей и сопровождением различных видов программного обеспечения (ПО) и баз данных (БД). Однако дальнейший анализ показывает, что с точки зрения публичноправового регулирования такого понимания оказывается недостаточно.

При этом следует также учитывать, что с точки зрения финансового менеджмента фи- 
нансовое участие в стартапах является венчурными рисковыми инвестициями. В тоже время в российском законодательстве фрагментарно урегулирован данный вид инвестиционных отношений, хотя законодательство России об инвестиционной деятельности насчитывает не один десяток лет. Высокорисковые венчурные инвестиции по своей экономической природе создают повышенную угрозу для интересов всех участников инвестиционного процесса. Таким образом, публично-правовое регулирование служит тем самым балансиром, который должен с одной стороны создавать условия для развития цифровых стартапов, а с другой стороны, разграничивать и защищать интересы субъектов этих отношений.

Сущность публично-правового регулирования проявляется в том, что оно является одной из форм государственного воздействия на предпринимательскую деятельность. Другой формой подобного регулирования выступает государственная поддержка. Публично-правовое регулирование предпринимательской деятельности реализуется в различных форматах. Основными являются: 1) законодательное регулирование мер поддержки предпринимательства, включая цифровые стартапы, 2) создание инфраструктуры, обеспечивающей государственную поддержку малого и среднего предпринимательства. На примере анализа законодательно закрепленной системы мер, стимулирующих формирование цифровых стартапов, следует выделить несколько уровней такого регулирования.

Во-первых, это упомянутый выше федеральный закон от 24 июля 2007 г. № 209-ФЗ «О развитии малого и среднего предпринимательства в Российской Федерации», создающий режим благоприятствования для малого и среднего предпринимательства. В соответствии с пунктом 1 статьи 16 федерального закона поддержка субъектов малого и среднего предпринимательства включает в себя финансовую, в том числе гарантийную, имущественную, информационную, консультационную поддержку; поддержку в области подготовки, переподготовки и повышения квалификации их работников, поддержку в области инноваций и промышленного производства, ремесленничества, поддержку субъектов малого и среднего предпринимательства, осуществляющих внешнеэкономическую деятельность, поддержку субъектов малого и среднего предпринимательства, осуществляющих сельскохозяйственную деятельность.

Во-вторых, это система мер налоговоправового стимулирования, которая предусматривает применение субъектами малого и среднего предпринимательства специальных налоговых режимов - упрощенной системы налогообложения (УСН, гл. 26.2 Налогового кодекса) и патентной системы налогообложения (ПСН, гл. 26.5 Налогового кодекса). Эти специальные правовые режимы позволяют субъектам малого и среднего предпринимательства не уплачивать следующие налоги: а) налог на добавленную стоимость (НДС), б) налог на прибыль. Эти налоги создают серьезную финансовую нагрузку на бизнес, и государство предлагает заменить их иными платежами в рамках соответствующей системы налогообложения. Вместе с тем, необходимо учитывать, что для применения УСН налогоплательщик должен отвечать определенным показателям финансово-хозяйственной деятельности. Патентную же систему могут применять только индивидуальные предприниматели, осуществляющие определенные виды деятельности. В перечне подобных видов деятельности Налогового кодекса РФ устанавливает, в том числе, разработку компьютерного программного обеспечения (системного программного обеспечения, приложений программного обеспечения, баз данных, web-страниц, включая их адаптацию и модификацию, пп.62, п.2 ст.346.43 Налогового кодекса РФ).

В-третьих, внушительным блоком норм публично-правового регулирования, затрагивающим предпринимательскую деятельность и цифровые стартапы, являются нормы бюджетного права. Статья 80 Бюджетного Кодекса РФ и Правила от 14 июля 2020 года № 1041 [11] предусматривают предоставление бюджетных инвестиций юридическим лицам, которые не являются федеральными учреждениями и федеральными предприятиями, исходя из целей и задач, содержащихся в документах стратегического планирования Российской Федерации, поручений и указаний Президента Российской Федерации и поручений Правительства Российской Федерации.

B-четвертых, отметим нормы законодательства о контрактной системе, влияющие на формирование стартапов. Следует отметить, что в настоящее время нет единодушного мнения об отраслевой принадлежности норм, регламентирующих контрактную систему. Поскольку осве- 
щение данного вопроса не является предметом статьи, укажем, что с нашей точки законодательство о контрактной системе представляет собой составную часть бюджетно-правового регулирования, и устанавливает одну из возможных процедур исполнения бюджета и распоряжения бюджетными средствами. Федеральный закон «О контрактной системе в сфере закупок товаров, работ, услуг для обеспечения государственных и муниципальных нужд» от 05.04.2013 года № 44Ф3 [12] и изданные в его развитие подзаконные акты устанавливают специальные правила и квоты для государственных и муниципальных закупок у субъектов малого и среднего предпринимательства. В частности, в соответствии со ст.30 указанного закона объем закупок государственного (муниципального) заказчика у субъектов малого и среднего предпринимательства, реализующего инновационную продукцию, должна составлять не менее 15\%, а с 01.01.2022 года - не менее 25\% общего объема закупок.

Наряду с рассмотренными выше элементами публично-правового регулирования предпринимательской деятельности и малого и среднего предпринимательства в целом, следует упомянуть систему мер, введённых непосредственно для развития и поддержки цифровых стартапов.

Подобная система мер отразилась в следующих нормативных правовых актах стратегического управления:

1) значительная роль в формировании мер поддержки цифровых стартапов отведена Указу Президента Российской Федерации от 07.07.2011 года № 899 «Об утверждении приоритетных направлений развития науки, технологий и техники в Российской Федерации и перечня критических технологий Российской Федерации» [13]. Перечень приоритетных направлений, закрепленных в нем, направлен на создание цифровых технологий, их развитие в Российской Федерации.

2) цифровая трансформация и поддержка малого и среднего предпринимательства в указах Президента Российской Федерации от 7 мая 2018 года № 204 «О национальных целях и стратегических задачах развития Российской Федерации на период до 2024 года» [14] и от 21 июля 2020 года № 474 «О национальных целях развития Российской Федерации на период до 2030 года» [15] названы в числе приоритетных целей стратегического развития государства.

3) модернизация цифровой экономики и цифровых стартапов обозначены одним из приоритетов стратегического планирования. С целью решения задачи по обеспечению ускоренного внедрения цифровых технологий в экономике и социальной сфере, Правительством Российской Федерации сформирована национальная программа «Цифровая экономика Российской Федерации», в состав которой входят следующие федеральные проекты: «Нормативное регулирование цифровой среды»; «Кадры для цифровой экономики»; «Информационная инфраструктура»; «Информационная безопасность»; «Цифровые технологии»; «Цифровое государственное управление»; «Искусственный интеллект» [16]. В силу этого увеличилась роль публично-правового регулирования в этой области.

Рассмотрим наиболее частые проблемы, с которыми сталкиваются стартапы, в том числе и цифровые. Это - проблема привлечения финансирования и инвесторов. Для ее решения в российском законодательстве о предпринимательской деятельности в последние годы появились новые институты, в числе которых можно упомянуть, в частности, краудфандинг и конвертируемый займ. Краудфандинг - это финансовый термин, обозначающий один из методов привлечения инвестиций от большого количества сторонних лиц. До недавнего времени российское законодательство не регулировало подобный механизм инвестирования, однако развитие стартапов, в том числе, цифровых, вызвало к жизни специальное правовое регулирование этих отношений. Основополагающим нормативным актом, регулирующим краудфандинг в России, стал федеральный закон от 2 августа 2019 г. № 259-Ф3 «О привлечении инвестиций с использованием инвестиционных платформ и о внесении изменений в отдельные законодательные акты Российской Федерации». Принятие этого закона позволило с помощью инструментов публично-правового регулирования сбалансировать публичные интересы общества и государства с частными интересами инвесторов и лиц, привлекающих инвестиции (стартапы).

Законодатель ожидаемо не использует термин «краудфандинг», заменив его фразой: «деятельность по организации привлечения инвестиций», под которой понимает оказание услуг по содействию в инвестировании и услуг по привлечению инвестиций с использованием инвестиционной платформы. Федеральный закон от 
2 августа 2019 г. № 259-Ф3 позволяет привлекать инвестиции через инвестиционные платформы, операторами которых являются хозяйственные общества. Операторы инвестиционных платформ выполняют функции посредников, в том числе, финансовых, при заключении договоров между инвесторами и стартапами. Соответственно, операторы инвестиционных платформ должны быть включены в реестр Центрального Банка РФ. В качестве лиц, привлекающих инвестиции, могут выступать юридические лица и индивидуальные предприниматели, а инвесторами могут быть как юридические, так и физические лица. Примечательным стало обстоятельство, согласно которому инвестирование по указанным законам может осуществляться как путем предоставления займов и приобретения ценных бумаг, так и путем приобретения утилитарных цифровых прав. А с 01.01.2021 года в связи со вступлением в силу федерального закона от 31 июля 2020 года № 259-Ф3 «О цифровых финансовых активах, цифровой валюте и о внесении изменений в отдельные законодательные акты Российской Федерации» [17] - также и цифровые финансовые активы.

Легальное закрепление механизма краудфандинга в российском законодательстве существенно упростило привлечение инвестиций для стартапов. Развитием концепции краудфандинга стал федеральный закон от 02.07.2021 года № 354-Ф3 «О внесении изменений в отдельные законодательные акты Российской Федерации» [18], который в СМИ получил название закона о конвертируемом займе. Принципиальной идеей изменений, вносимых в законодательство Федеральным законом от 02.07.2021 года, является предоставление инвесторам права трансформации ранее предоставленного займа в инвестиции. В соответствии с понятием договора конвертируемого займа, включенного в федеральный закон от 26 декабря 1995 года № 208-ФЗ «Об акционерных обществах» [19], таким договором признается договор займа, предусматривающий право займодавца вместо возврата всей или части суммы займа и выплаты всех или части процентов за пользование займом при наступлении срока и (или) иных обстоятельств, предусмотренных этим договором, потребовать от заемщика, являющегося непубличным обществом, размещения займодавцу дополнительных акций определенной категории (типа) (ст.32.3 федерального закона «Об акционерных обществах»). В сфере деятельности обществ с ограниченной ответственностью понятие договора конвертируемого займа изложена несколько иначе: договор займа, предусматривающий право займодавца вместо возврата всей или части суммы займа и выплаты всех или части процентов за пользование займом при наступлении срока и (или) иных обстоятельств, предусмотренных этим договором, потребовать от общества увеличения его уставного капитала, увеличения номинальной стоимости и размера доли займодавца - участника общества и уменьшения размера долей иных участников общества, а если займодавцем является третье лицо - принятия займодавца в общество, приобретения займодавцем доли в уставном капитале общества и уменьшения размера долей участников общества (ст.19.1 федерального закона от 8 февраля 1998 года № 14-Ф3 «Об обществах с ограниченной ответственностью») [20].

Несмотря на то, что понятия договора конвертируемого займа в отношении акционерных обществ и обществ с ограниченной ответственностью отличаются, суть отношений остается неизменной. Заемщику предоставляется право трансформации своего займа в инвестиции. Принятие данного закона решило сразу несколько важных для сферы стартапов вопросов: легализовало конструкцию конвертируемого займа в российской практике и сбалансировало интересы инвесторов и стартапа, вводя дополнительные инструменты защиты (нотариальное заверение договора конвертируемого займа и возможность требовать исполнения договора в судебном порядке).

Рассматривая систему публично-правового регулирования предпринимательской деятельности в сфере цифровых стартапов нельзя не упомянуть «Налоговый ИТ-маневр». Так в прессе назвали федеральный закон № 265-Ф3 «О внесении изменений в часть вторую Налогового кодекса Российской Федерации» [21]. В соответствии с внесенными изменениями на территории Российской Федерации освобождается от обложения НДС реализация исключительных прав на программы для электронных вычислительных машин и базы данных, включенные в единый реестр российских программ для электронных вычислительных машин и баз данных, прав на использование таких программ и баз данных (включая обновления к ним и дополнительные функциональные возможности). Также 
для российских организаций, которые осуществляют деятельность в области информационных технологий, разрабатывают и реализуют разработанные ими программы для ЭВМ, базы данных на материальном носителе или в форме электронного документа по каналам связи и (или) оказывают услуги (выполняют работы) по разработке, адаптации, модификации программ для ЭВМ, баз данных (программных средств и информационных продуктов вычислительной техники), устанавливают, тестируют и сопровождают программы для ЭВМ, базы данных, снижен налог на прибыль (с 20\% до 3\%), а также применяются пониженные тарифы страховых взносов.

Хотя этот маневр в большей мере ориентирован на снижение налоговой нагрузки на организации, находящиеся на общей системе налогообложения, положения, предусматривающие снижение страховых взносов, имеют значение и для стартапов в цифровой сфере (однако, отметим, что и в данном случае речь идет о стартапах, имеющих организационно-правовую форму юридического лица).

Кроме создания нормативной базы для инвестирования и закрепления мер финансовой поддержки, необходимо также упомянуть создание инфраструктурных механизмов поддержки малого и среднего предпринимательства, в том числе и цифровых стартапов. Основы такой формы поддержки прямо следуют из ст.22 федерального закона о развитии малого и среднего предпринимательства от 24 июля 2007 г. № 209-Ф3, в соответствии с которой оказание поддержки субъектам малого и среднего предпринимательства в области инноваций и промышленного производства органами государственной власти и органами местного самоуправления может осуществляться, в том числе, в виде создания организаций, образующих инфраструктуру поддержки субъектов малого и среднего предпринимательства и оказывающих поддержку субъектам малого и среднего предпринимательства, в том числе технопарков, центров коммерциализации технологий, технико-внедренческих и научно-производственных зон, и обеспечения деятельности таких организаций.

Безусловно, значимыми мерами государственной поддержки цифровых стартапов следует считать создание инновационного центра «Сколково»[22], а также планируемое создание инновационных научно-технологических центров, предусмотренное федеральным законом от 29 июля 2017 г. № 216-Ф3 «Об инновационных научно-технологических центрах и о внесении изменений в отдельные законодательные акты Российской Федерации» [23], который в СМИ успели окрестить «законом о технологических долинах». В соответствии с этим федеральным законом уже созданы и запущены два инновационных научно-технологических центра (ИНТЦ) - ИНТЦ «Сириус» (постановление Правительства Российской Федерации № 1428 от 8 ноября 2019 года) и ИНТЦ МГУ «Воробьевы горы» (постановление Правительства Российской Федерации № 332 от 28 марта 2019 года), которые специализируются преимущественно в области информационных технологий.

Следует отметить Указ Президента Российской Федерации от 05.06.2015 г. № 287 «О мерах по дальнейшему развитию малого и среднего предпринимательства» [24]. В соответствии с Указом создается акционерное общество «Федеральная корпорация по развитию малого и среднего предпринимательства», основными задачами которого являются, в том числе, оказание финансовой, инфраструктурной, имущественной, юридической, методологической и иной поддержки субъектам малого и среднего предпринимательства. Таким образом, законодатель стремится оперативно реагировать на новые формы поддержки предпринимательства, которые предлагаются рыночной экономикой.

Российский законодатель стремится оперативно и адекватно реагировать на изменения отношений в области предпринимательской деятельности. Анализ развития системы публично-правового регулирования предпринимательской деятельности в современных российских условиях показывает, что регламентация развития цифровых стартапов в России осуществляется как путем установления механизмов поддержки и регулирования их деятельности, так и путем создания необходимой инфраструктуры. За последние несколько лет в российском законодательстве появились новые инструменты поддержки цифровых стартапов. К ним следует отнести как традиционные меры поддержки, через систему бюджетных и налоговых льгот, так и формализацию механизмов венчурного инвестирования (краудфандинг и конвертируемый займ). 


\section{Библиографический список}

1. Гольдштейн Г.Я. Основы менеджмента. Таганрог, 2003. С. 15-20.

2. Об утверждении положения о стимулировании изобретательской и инновационной деятельности в ОАО «РЖД»: Распоряжение ОАО «РЖД»: от 29 декабря 2011 г. № 2823p. Режим доступа: https://internet.garant. $\mathrm{ru} / \# /$ document/ 70785650/paragraph/131/doclist/11186/

3. Об участии малых предприятий в программе «Старт»: письмо Министерства экономического развития РФ от 24 июля 2014 г. № 17438-ОФ/Д19. Режим доступа: https://internet.garant.ru/\#/document/70832660/ paragraph/1/doclist/11186/ showentries/false/highlight/

4. Об участии малых предприятий в программе «Старт»: письмо Министерства экономического развития РФ от 24 июля 2014 г. № 17438-ОФ/Д19. Режим доступа: https://internet.garant.ru/\#/document/70832660/ paragraph/1/doclist/11186/ showentries/false/highlight/

5. Янковский Р. М. Закон Стартапа. М., 2017. С.17.

6. Минцифры России выделяет 7.1 млрд. рублей на гранты для ИТ-проектов: информация Министерства цифрового развития, связи и массовых коммуникаций РФ от 22 сентября 2020 г. Режим доступа: https://internet. garant.ru /\#/document/74669540/paragraph/1/doclist/ 11186/showentries/false/highlight/10

7. О направлении методических рекомендаций по программам развития: письмо Федерального агентства научных организаций от 13 мая 2016 г. № 007-18.1-14/AM-1655. Режим доступа: https://internet.garant. ru/\#/document/71401444/ paragraph/200/doclist/11186/showentries/false/highlight/8

8. Паспорт «дорожной карты» развития высокотехнологичной области «квантовые коммуникации» на период до 2024 года, утв. Минцифры России 27 августа 2020 г. Режим доступа: https://internet.garant.ru/\#/ document/400843720/ paragraph/3400/doclist/11186/showentries/false/highlight/11

9. О критериях отнесения товаров, работ, услуг к инновационной продукции и (или) высокотехнологичной продукции: постановление Правительства РФ от 15 июня 2019 г. № 773 // Собр. законодательства Рос. Федерации. 2019. № 25. ст. 3270.

10. Модель и параметры мониторинга университетских центров инновационного, технологического и социального развития регионов (Приоритетный проект «Вузы как центры пространства создания инноваций»): письмо Министерства образования и науки РФ от 31 августа 2017 г. № ЛО-1754/05. Режим доступа: https:// internet.garant.ru/\#/document/71765540/paragraph/4/doclist/11186/showentries/false/highlight/7

11. Правила принятия решений о предоставлении из федерального бюджета бюджетных инвестиций юридическим лицам, не являющимся федеральными государственными учреждениями и федеральными государственными унитарными предприятиями, на цели, не связанные с осуществлением капитальных вложений в объекты капитального строительства, находящиеся в собственности указанных юридических лиц (их дочерних обществ), и (или) приобретением ими объектов недвижимого имущества, утв. постановлением Правительства РФ от 14 июля 2020 г. № 1041 // Собр. законодательства Рос. Федерации. 2020. № 29. Ст. 4686.

12. Собр. законодательства Рос. Федерации. 2013. № 14. Ст. 1652.

13. http://www.kremlin.ru/acts/bank/33514; дата обращения: 26.09.2021

14. http://www.kremlin.ru/acts/bank/43027; дата обращения: 26.09.2021

15. http://www.kremlin.ru/acts/bank/45726; дата обращения 26.09.2021

16. паспорт программы: http://static.government.ru/media/files/urKHm0gTP PnzJlaKw3M5cNLo6gczMkPF.pdf; дата обращения: 26.08 .2021

17. Собр. законодательства Рос. Федерации. 2020. № 31 (часть I). Ст. 5018

18. Собр. законодательства Рос. Федерации. 2021. № 27 (часть I). Ст. 5182

19. Собр. законодательства Рос. Федерации. 1996. № 1. Ст. 1; 2001. № 33. Ст. 3423; 2006. № 1. Ст. 5; 2012. № 53. Ст. $7607 ; 2015$. № 27. Ст. 4001

20. Собр. законодательства Рос. Федерации. 1998. № 7. Ст. 785; 2009. № 1. Ст. 20; № 52. Ст. 6428; 2015. № 27. Ст. 4000 .

21. Собр. законодательства Рос. Федерации. 2020. № 31 (часть I). Ст. 5024.

22. Об инновационном центре «Сколково»: федеральный закон от 28 сентября 2010 г. № 244-Ф3 // Собр. законодательства Рос. Федерации. 2010. № 40. Ст. 4970

23. Об инновационных научно-технологических центрах и о внесении изменений в отдельные законодательные акты Российской Федерации: Федеральный закон от 29 июля 2017 г. № 216-Ф3 // Собр. законодательства Рос. Федерации. 2017. № 31 (часть I). ст. 4765

24. http://www.kremlin.ru/acts/bank/39747; дата обращения: 26.09.2021 